\title{
Commentary \\ Detecting volume responsiveness and unresponsiveness in intensive care unit patients: two different problems, only one solution
}

\author{
Jean-Louis Teboul ${ }^{1,2}$ and Xavier Monnet ${ }^{1,2}$ \\ ${ }^{1}$ Service de réanimation médicale, CHU Bicêtre, AP-HP, Le Kremlin-Bicêtre, F-94270, France \\ ${ }^{2} E A$ 4046, faculté de médecine Paris-Sud, Univ Paris-Sud, Le Kremlin-Bicêtre, F-94270, France
}

Corresponding author: Jean-Louis Teboul, jean-louis.teboul@bct.aphp.fr

Published: 10 August 2009

Critical Care 2009, 13:175 (doi:10.1186/cc7979)

This article is online at http://ccforum.com/content/13/4/175

(c) 2009 BioMed Central Ltd

See related research by Thiel et al., http://ccforum.com/content/13/4/R111

\begin{abstract}
Policies of fluid administration/restriction in critically ill patients have evolved over recent years. Abundant fluid resuscitation is encouraged during the early stage of severe sepsis. But a conservative fluid strategy is recommended in later stages, in particular when lungs are injured. Both strategies are risky if uncontrolled. Tests detecting volume unresponsiveness at any moment of fluid resuscitation or detecting volume unresponsiveness at any moment of fluid restriction would help to better assess the benefit/risk ratio of continuing such strategies. Measuring the short-term hemodynamic changes during passive leg raising can be reliably used for that purpose in both situations, even when patients are breathing spontaneously.
\end{abstract}

In this issue of Critical Care, Thiel and colleagues [1] present a new method for tracking the changes in cardiac output in response to passive leg raising (PLR), one of the tests recently proposed to predict volume responsiveness in critically ill patients [2]. Recent review articles have emphasised the relevance of using dynamic indices such as pulse pressure variation and stroke volume variation for that purpose [3-5]. Nevertheless, the respiratory variation of stroke volume cannot be used in cases of spontaneous breathing $[6,7]$ or low tidal volume ventilation [8]. In such problematic cases, PLR, by acting as an endogenous volume challenge, represents a helpful tool for predicting fluid responsiveness [2]. Compared with the classical fluid challenge [9], it has the advantage of being rapidly and totally reversible [2]. The potential risks of fluid infusion are thus expected to be minimised, which is important to consider in critically ill patients in whom multiple challenges are often necessary. Confirming previous reports [6,10], Thiel and colleagues [1] have shown that PLR is a reliable test for predicting volume responsiveness in mechanically ventilated patients, even in those with spontaneous breathing activity. For tracking the changes in cardiac output during the postural manoeuvre, they used a transcutaneous continuous-wave Doppler ultrasound device able to measure blood flow across the aortic or the pulmonary valve. This totally non-invasive method is assumed to be less user-dependent than the classical Doppler echocardiography. Unlike the oesophageal Doppler technique, this device can be applied in non-intubated patients. As predicting volume responsiveness using such a simple method is very attractive, further confirmation studies are necessary.

Another interesting finding of the study by Thiel and colleagues [1] was the high rate (54\%) of patients who did not respond to fluid administration, confirming recent reports $[4,7,11]$. This issue must be discussed in line with the recent evolution of ideas and policies in terms of fluid administration in critically ill patients. The concept of increasing cardiac output to correct an occult oxygen debt in critically ill patients was developed during the '90s. Although it did not lead to improved outcome of intensive care unit (ICU) patients enrolled in randomised studies [12,13], this concept promoted the idea that critically ill patients are often underresuscitated, even in the absence of hypotension or of any sign of blood volume deficit. The study by Rivers and colleagues [14] emphasised the importance of increasing cardiac output by using aggressive fluid administration in the early phase of severe sepsis. This concept has been well adopted by pre-hospital, emergency care and critical care physicians as witnessed by the fact that more than $50 \%$ of ICU patients are volume-unresponsive in recent studies $[1,4,7,11]$. However, volume unresponsiveness is an abnormal state since it indicates that the patient's heart operates

$\mathrm{CVP}=$ central venous pressure $; \mathrm{ICU}=$ intensive care $\mathrm{unit} ; \mathrm{PLR}=$ passive leg raising. 
on the flat part of the Frank-Starling curve, as does a failing heart. In this condition, further fluid administration should dramatically increase cardiac filling pressures with inherent high risks of pulmonary oedema development, in particular in cases of altered pulmonary vascular permeability. In this regard, there is now increasing evidence that fluid overload negatively impacts the outcome of critically ill patients $[15,16]$.

We can schematically distinguish between two opposite situations that are frequently encountered in the ICU. The first one is represented by the management of patients in the early phase of sepsis. The Surviving Sepsis Campaign [17] recommends that fluid be administered until the central venous pressure (CVP) reaches 8 to $12 \mathrm{~mm} \mathrm{Hg}$ (or more in mechanically ventilated patients) provided that the central venous oxygen saturation is less than 70\%. As the CVP cannot identify volume-unresponsive patients [11], such an attitude could result in fluid overload of most of those patients. A test capable of reliably detecting volume unresponsiveness at any moment of fluid resuscitation would help to better assess the benefit/risk ratio of continuing such a strategy.

The second situation is represented by the management of patients with lung injury after the early stage has passed. A conservative fluid strategy is now recommended in this situation [18]. However, an uncontrolled fluid restriction attitude (diuretics or ultrafiltration) could result in marked volume depletion and subsequent organ hypoperfusion. A test capable of reliably detecting when the degree of volume responsiveness at any moment of fluid restriction is too high would help to assess the benefit/risk ratio of continuing such a strategy.

The ICU physician must frequently face these two opposite situations. Fortunately, the tests developed to detect volume responsiveness can also serve to detect volume unresponsiveness. Among different tests, PLR is probably one of the most valuable since it can be used in ICU patients with spontaneous breathing activity.

\section{Competing interests}

J-LT and XM are members of the Medical Advisory Board of Pulsion Medical Systems AG (Munich, Germany).

\section{References}

1. Thiel SW, Kollef $\mathrm{MH}$, Isakow W: Non-invasive volume measurement and passive leg raising predict volume responsiveness in medical ICU patients: an observational cohort study. Crit Care 2009, 13:R111.

2. Monnet $\mathrm{X}$, Teboul JL: Passive leg raising. Intensive Care Med 2008, 34:659-663.

3. Michard F, Teboul JL: Using heart-lung interactions to assess fluid responsiveness during mechanical ventilation. Crit Care 2000, 4:282-289.

4. Michard F, Teboul JL: Predicting fluid responsiveness in ICU patients: a critical analysis of the evidence. Chest 2002, 121: 2000-2008.

5. Marik PE, Cavallazzi R, Vasu T, Hirani A: Dynamic changes in arterial waveform derived variables and fluid responsiveness in mechanically ventilated patients: a systematic review of the literature. Crit Care Med 2009, Jul 13. [Epub ahead of print].

6. Monnet X, Rienzo M, Osman D, Anguel N, Richard C, Pinsky MR, Teboul JL: Passive leg raising predicts fluid responsiveness in the critically ill. Crit Care Med 2006, 34:1402-1407.

7. Heenen S, De Backer D, Vincent JL: How can the response to volume expansion in patients with spontaneous respiratory movements be predicted? Crit Care 2006, 10:R102.

8. De Backer D, Heenen S, Piagnerelli M, Koch M, Vincent JL: Pulse pressure variations to predict fluid responsiveness: influence of tidal volume. Intensive Care Med 2005, 31:517-523.

9. Vincent JL, Weil MH: Fluid challenge revisited. Crit Care Med 2006, 34:1333-1337.

10. Lamia B, Ochagavia A, Monnet X, Chemla D, Richard C, Teboul $\mathrm{JL}$ : Echocardiographic prediction of volume responsiveness in critically ill patients with spontaneously breathing activity. Intensive Care Med 2007, 33:1125-1132.

11. Osman D, Ridel C, Ray P, Monnet X, Anguel N, Richard C, Teboul $\mathrm{JL}$ : Cardiac filling pressures are not appropriate to predict hemodynamic response to volume challenge. Crit Care Med 2007, 35:64-68.

12. Hayes MA, Timmins AC, Yau EH, Palazzo M, Hinds CJ, Watson $D$ : Elevation of systemic oxygen delivery in the treatment of critically ill patients. N Engl J Med 1994, 330:1717-1722.

13. Gattinoni L, Brazzi L, Pelosi P, Latini R, Tognoni G, Pesenti A, Fumagalli R: A trial of goal-oriented hemodynamic therapy in critically ill patients. SvO2 Collaborative Group. N Engl J Med 1995, 333:1025-1032.

14. Rivers E, Nguyen B, Havstad S, Ressler J, Muzzin A, Knoblich B, Peterson E, Tomlanovich M: Early Goal-Directed Therapy Collaborative Group. Early goal-directed therapy in the treatment of severe sepsis and septic shock. N Engl J Med 2001, 345: 1368-1377.

15. Vincent JL, Sakr Y, Sprung CL, Ranieri VM, Reinhart K, Gerlach H, Moreno R, Carlet J, Le Gall JR, Payen D: Sepsis Occurrence in Acutely III Patients Investigators. Sepsis in European intensive care units: results of the SOAP study. Crit Care Med 2006, 34:344-353.

16. Payen D, de Pont AC, Sakr Y, Spies C, Reinhart K, Vincent JL: Sepsis Occurrence in Acutely III Patients (SOAP) Investigators. A positive fluid balance is associated with a worse outcome in patients with acute renal failure. Crit Care 2008, 12:R74.

17. Dellinger RP, Levy MM, Carlet JM, Bion J, Parker MM, Jaeschke R, Reinhart K, Angus DC, Brun-Buisson C, Beale R, Calandra T, Dhainaut JF, Gerlach H, Harvey M, Marini JJ, Marshall J, Ranieri M, Ramsay G, Sevransky J, Thompson BT, Townsend S, Vender JS, Zimmerman JL, Vincent JL: Surviving Sepsis Campaign guidelines for management of severe sepsis and septic shock: 2008. Crit Care Med 2008, 36:296-327.

18. Wiedemann HP, Wheeler AP, Bernard GR, Thompson BT, Hayden D, deBoisblanc B, Connors AF Jr., Hite RD, Harabin AL: Comparison of two fluid-management strategies in acute lung injury. N Engl J Med 2006, 354:2564-2575. 